\title{
West syndrome - Diagnostic dilemma in a month old infant without typical electroencephalographic features: A case report
}

\section{Subedi $K^{1}$, Basnet $R^{2}$, Bhandari $B^{3}$, Gongal $S^{4}$, Rajak $A^{5}$}

${ }^{1}$ Kiran Subedi, Registrar, International Friendship Children's Hospital, Kathmandu; ${ }^{2}$ Rydam Basnet, Lecturer, Kathmandu Medical College Teaching Hospital, Kathmandu; ${ }^{3}$ Bikash Bhandari, Lecturer, Devdaha Medical College and Research Institute, Rupandehi; ${ }^{4}$ Sonsy Gongal, Lecturer, KIST Medical College, Lalitpur; ${ }^{5}$ Ashik Rajak, Department of Paediatrics, Kathmandu Medical College Teaching Hospital, Kathmandu, Nepal.

\begin{abstract}
Infantile spasm constitutes $2 \%$ of childhood epilepsies but $25 \%$ of epilepsy with onset in the first year of life. The rate of infantile spasm is estimated to be 2.5-6.0 cases per 10,000 live births. Its prevalence rate is 1.5-2.0 cases per 10,000 children aged 10 years or younger. Ninety percent of infantile spasms begin in infants younger than 12 months with a peak onset at age 4-6 months.

We report a case of 45 days old male child who had onset of flexor spasms since one month of age which is an unusual age of onset of West syndrome. The symptoms were initially thought as a simple startle response by the mother. This is a rare case because of its age of onset and lack of typical electroencephalographic features. Although the electroencephalography showed abnormal pattern suggesting seizure disorder, the frequently encountered pattern of hypsarrhythmia seen in children with infantile spasm was not seen in this case. It was difficult to assess developmental regression in a month old child who in subsequent visits had some degree of developmental delay. Hence fulfilling two of the three criteria's for the diagnosis.
\end{abstract}

Key words: Hypsarrhythmia; Infantile spasms; West syndrome.

DOI: https://doi.org/10.3126/jkmc.v8i2.28175

\section{INTRODUCTION}

W est syndrome presents between the ages of 2 and 12 months and consists of a triad of infantile spasms that usually occur in clusters (particularly in drowsiness or upon arousal), developmental regression, and a typical EEG picture called hypsarrhythmia'. Hypsarrhythmia is a high-voltage, slow, chaotic background with multifocal spikes. Although the diagnosis can be made even if one of the three elements is missing (according to the international classification) ${ }^{1}$ the majority (90 percent) of affected children present at less than one year of age, with a range from one day to 4.5 years of age $\mathrm{e}^{2-3}$. The peak incidence of onset (50 to 77 percent) is between three and seven months; and the onset of infantile spasms after 18 months is rare ${ }^{4}$. The

Address for correspondence

Dr. Kiran Subedi

Registrar

International Friendship Children's Hospital, Kathmandu, Nepal

E-mail: bpsubedi2010@hotmail.com true age of onset may be uncertain because infantile spasms may be initially mistaken for other conditions, such as hyperirritability, exaggerated startle responses, and/or colic. West syndrome is an age-dependent expression of a damaged brain, and most patients with infantile spasms have some degree of developmental delay.

\section{CASE REPORT}

A 45-day-old male baby from Butwal was admitted after being referred for diagnosis and management from a sub urban hospital. According to the parents, baby was normal at birth and until 14 days when he started having abnormal jerky movements of head, neck and limbs. It was associated with flexion of upper and lower extremities. The movements persisted to 10-20 jerks at a time and several times a day. The first episode was associated with up-rolling of the eyes and frothing at the mouth buturine and stool were not noticed at the time of the jerks. There was no history of injury to the 
head, the child did not have fever, the baby was feeding well and thriving. There was no history of abnormal color orsmell of urine or body odor. The mother had regular antenatal visits and there was no history of maternal fever or rashes. The baby was born at term via lower segment caesarean section (LSCS) for gestational hypertension with birth weight 3500 grams and post natal events were uneventful. The immunization history showed that BCG, OPV, Hemophilus B, Hepatitis B and DPT were administered and was up to date for the age.

On initial examination, the vitals were stable with temperature 98.4 degrees Fahrenheit, heart rate - 120 beats per minute, respiratory rate- 36 breaths per minute and saturation of $97 \%$ in room air. There were no neurocutaneus markers, shagreen patch, ash leaf macules or neurofibromas. No facial dysmorphism was seen. There was no pallor, cyanosis, icterus, edema, lymphadenopathy or dehydration. The weight of the child was 5.8 kilograms ( $90^{\text {th }}$ percentile), length was 57 centimeters $\left(50^{\text {th }}\right.$ percentile), and head circumference was 40 centimeters ( $70^{\text {th }}$ percentile). His cardiovascular, respiratory, gastrointestinal, nervous system examinations were normal.

Laboratory investigations revealed anemia with haemoglobin-9.9g/dl, white blood cell count- $10,500 / \mu \mathrm{L}$, neutrophil- 38, lymphocyte-59, eosinophil-02, basophil01 , random blood sugar- $76 \mathrm{mg} / \mathrm{dl}$, urea - 32 , creatinine - 0.7 , sodium - 142 , potassium- 4.5, C-reactive proteinnormal. Electroencephalogram (EEG) was suggestive of abnormal inter-seizure pattern, no hypsarrythmia and magnetic resonance imaging (MRI) was normal ruling out structural brain defects as a cause of seizure. To rule out common metabolic disorders urine for organic and keto acids were done which was negative and venous pH was normal.

\section{REFERENCES}

1. Taghdiri MM, Nemati $H$. Infantile spasm: a review article. Iran J Child Neurol. 2014 Summer; 8(3):1-5. [PubMed]

2. Pellock JM, Hrachovy R, Shinnar S et al. Infantile spasms: a U.S. consensus report. Epilepsia. 2010; 51:2175. [DOI]

3. Trevathan E, Murphy CC, Yeargin-Allsopp M. The descriptive epidemiology of infantile spasms among Atlanta children.Epilepsia. 1999; 40:748. [DOI]
The baby was started on tablet prednisolone. Along with the steroid the baby was given tablet aciloc, pyridoxine multivitamins, calcium and vitamin D supplementation was done. The baby was then discharged after the frequency of spasms decreased after a week with regular blood pressure checkups and sugar in urine.

\section{DISCUSSION}

The long-term overall prognosis for patients with infantile spasm is poor and is directly related to the condition's etiology ${ }^{5}$. Infants with idiopathic West syndrome have a better prognosis than infants with symptomatic West syndrome. Only $14 \%$ of infants with symptomatic West syndrome have normal or borderline-normal cognitive development, compared with $28-50 \%$ of infants with idiopathic West syndrome ${ }^{6}$. Mental retardation is severe in $70 \%$ of patients, often with psychiatric problems such as autistic features or hyperactivity. Favorable prognostic factors also include the following: Cryptogenic or idiopathic etiology, age of onset of over 4 months, absence of atypical spasms and partial seizures, absence of asymmetrical EEG abnormalities, short time from onset to treatment, early and sustained response to treatment. Hence in our case the diagnosis was difficult because of the early age of onset and difficulty in assessment of developmental regression due to the same. The child then came to the OPD at 4 months of age and was not able to hold the neck and social smile was also delayed thus fulfilling two of the three criteria's of the West Syndrome.

\section{CONCLUSION}

Hence, a child presenting with West syndrome at an early age can be a diagnostic challenge as developmental assessment can be challenging. So, a strong suspicion and regular follow-up is the key in making the correct diagnosis and subsequent management.

4. Vigevano F, Fusco L, Cusmai R, et al. The idiopathic form of West syndrome. Epilepsia. 1993; 34:74. [DOI]

5. Karvelas G, Lortie A, Scantlebury MH, Duy PT, Cossette $\mathrm{P}$, Carmant L. A retrospective study on aetiology based outcome of infantile spasms. Seizure. 2009 Apr;18(3):197-201. [DOI]

6. Lux AL, Osborne JP. The influence of etiology upon ictal semiology, treatment decisions and long-term outcomes in infantile spasms and West syndrome. Epilepsy Res. 2006 Aug; 70Suppl 1:S77-86. [DOI] 